Res Pública Revista de Historia de las Ideas Políticas

ISSN: $1131-558 \mathrm{X}$

http://dx.doi.org/10.5209/rpub.65958

\title{
El indianismo de Álvaro García Linera
}

\author{
Jian Ren*; Ruohui Ma**
}

Recibido: 7 de octubre de 2019 / Aceptado: 15 de febrero de 2020

Resumen. El objetivo de este trabajo consiste en el intento de configurar nuevos actores indígenas en el terreno político, investigando para ello la genealogía del pensamiento indianista de Álvaro García Linera. Este indianismo se ha forjado a su vez sobre la base de Reinaga, además de estar vinculado con Valcárcel, del cual recoge el modelo de reorganización de las estructuras comunitarias indígenas; con Mariátegui, en lo ateniente al reconocimiento de la base social comunista de la comunidad indígena; y con Fanon respecto al uso de la violencia en la revolución india y la autoproducción de la lógica anticolonial y descolonizada. En realidad, se trata del indianismo katarista que rompe el desencuentro entre marxismo e indigenismo. Esta reconexión permite asumir nuevos sujetos políticos, fuera del determinismo económico y de la centralidad de la clase trabajadora. Así parece necesario admitir que el indianismo ofrece nuevas meditaciones políticas sobre la construcción de la plurinacionalidad boliviana.

Palabras clave: indigenismo; indianismo; marxismo; Fausto Reinaga; Álvaro García Linera.

\section{[en] The Indianism of Álvaro García Linera}

\begin{abstract}
The objective of this work is the attempt to configure new indigenous actors in the political field, investigating the genealogy of Álvaro García Linera's Indianist thought. This Indianism has been forged in turn on the basis of Reinaga, in addition to being linked to Valcárcel, which includes the model of reorganization of indigenous community structures; with Mariátegui, regarding the recognition of the communist social base of the indigenous community; and with Fanon regarding the use of violence in the Indian revolution and the self-production of anti-colonial and decolonized logic. Actually, it is about the katarist Indianism that breaks the disagreement between Marxism and indigenism. This reconnection makes it possible to assume new political subjects, outside the economic determinism and the centrality of the working class. Thus it seems necessary to admit that Indianism offers new political meditations on the construction of bolivian plurinationality.
\end{abstract} Keywords: Indigenism; Indianism; Marxism; Fausto Reinaga; Álvaro García Linera.

Sumario. 1. Indianismo y Fausto Reinaga. 2. Indianismo, katarismo y Álvaro García Linera. 3. Bibliografía.

Cómo citar: Ren, J.; Ma, R. (2020). El indianismo de Álvaro García Linera. Res Pública. Revista de Historia de las Ideas Políticas, 23(1), 67-73.

"De hecho, hoy se puede decir que la concepción del mundo de corte emancipativo más importante e influyente en la actual vida política del país es el indianismo, y que es el núcleo discursivo y organizativo de lo que hoy podemos denominar la nueva izquierda"2. Tanto el indianismo como el marxismo, para Álvaro García Linera, desempeñan roles insustituibles en la construcción del Estado plurinacional. No obstante, hasta principios del siglo XXI, en América Latina estos dos pensamientos fundamentalmente revolucionarios se mantenían divorciados desde hacía aproximadamente una centena de años, debido a que los marxistas primitivos no habían conocido ni el mundo ni las fuerzas indígenas. Aunque posteriormente los marxistas nacionalistas intentaron incluir a los indios en sus planteamientos ideológicos, en el fondo se referían siempre a una inclusión de base subordinada que implicaba exclusivamente a los cholos. Por ello, en Bolivia, el indianismo ha surgido no solo en contra del marxismo, sino también del nacionalismo revolucionario. Curiosamente, desde el punto de vista de García Linera, estas dos ideologías, que en un principio se encontraban contrapuestas, han devenido convergentes a través de dos razonamientos que han dominado el panorama ideológico reciente y están vinculados actualmente con el proyecto de construcción de la plurinacionalidad. En esta sección voy a tratar de averiguar tanto

\footnotetext{
Universidad Complutense de Madrid

oliren@foxmail.com

** Universidad Complutense de Madrid

ma2005xisu@yahoo.com

1 A. García Linera, La potencia plebeya, Buenos Aires, Prometeo-Clasco, 2008, p. 495.
} 
los motivos de su desencuentro como los de su posterior avenencia con el objetivo de reflexionar sobre los posibles itinerarios del desarrollo del pensamiento marxista e indianista en la era del postimperialismo.

\section{Indianismo y Fausto Reinaga}

Pensando en términos históricos, el indigenismo se trata de la iniciativa ideológica que aspira a terminar con la exclusión de los indios. Sin embargo, esta iniciativa no hace referencia a una verdadera incorporación de los mismos en la vida social, sino a una ficticia, porque el indigenismo contemporáneo solo se compromete a modernizar a los indígenas marginados incluyéndolos "de manera subordinada a la hegemonía mestiza"2. Es decir, bajo el pensamiento del indigenismo, lo mestizo (en lugar de lo colonizador) y lo criollo siguen oprimiendo a lo indígena, pero de un modo más hábil y camuflado, de tal modo que podemos llamarlo "neocolonización humanizada". Desde la perspectiva indigenista, los indios no dejan de ser sujetos subalternos porque, según su teoría, ellos mismos todavía no se han convertido en sujetos políticos de autoidentificación y autogobernación. Así que se puede decir que los movimientos indigenistas impulsados hasta ahora son actividades destinadas a transformar a los indios en mestizos en nombre de la búsqueda de la inclusión, pero efectuando con tales actos un proceso que termina desindianizando toda la sociedad.

El indianismo, en comparación con el indigenismo, pone un mayor énfasis en el valor que han tenido los indios en la marcha de la historia latinoamericana, pues los considera como protagonistas tanto de las luchas anteriores a nuestra época como de las revoluciones posteriores que se darán en el decurso histórico y cuyo fin será acabar con su condición subordinada construyendo así la base de su autonomía y su autoconfirmación. Entonces, en cierta manera, el indianismo va más allá del indigenismo, pues reorganiza al "pueblo indígena para que transite desde el indigenismo hasta la autonomía política"3. Ahora bien, bajo la perspectiva de García Linera, cuando hablamos de la construcción del concepto del indianismo hay una figura que no podemos ignorar, que es la del pensador indígena boliviano Fausto Reinaga. Así pues, ¿de qué se trata el indianismo? ¿Cómo se posiciona respecto a la figura inicial de Reinaga? Veamos ante todo el siguiente texto:

El indianismo es el discurso y el proyecto político indio de transformación de las condiciones de opresión y explotación vigentes sobre la mayoría india de Bolivia por parte de las élites blancas y mestizas. [...] Su indianismo [de Reinaga] reivindica el término indio como auto denominación de la población originaria, y rechaza el de indígena, que deriva del indigenismo, o el de campesino, impuesto a partir de la reforma agraria de $1953^{4}$.

2 F. Escárzaga, "El pensamiento indianista de Fausto Reinaga", La Migraña, Revista de análisis político, 20, 2016, p. 70.

3 C. Sánchez, Los pueblos indigenas: del indigenismo a la autonomía, México, D.F., Siglo XXI, 1999.

4 F. Escárzaga, op. cit., p. 72.
El diagnóstico de Reinaga acerca de la sociedad boliviana dio lugar al replanteamiento de la temática indígena a base de impugnar las posiciones de los nacionalistas revolucionarios mestizos y de los marxistas indigenistas. De hecho, Reinaga procura reconfigurar el itinerario político para que vuelvan los indios al poder, lo cual, bajo su consideración, se conseguirá a través de interpelar y criticar el Estado-nación. El Estado nacionalista boliviano, fundado sobre la base de la nación mestiza, excluyó en su formación a los pueblos originarios a través de un proceso de homogeneización que se impulsó desde el sentido común de la clase dominante mestiza, y que en realidad los diluyó a la vez dentro de la sociedad, desindianizando la etnicidad propia de esos pueblos. De este modo, lo indígena viene perdiendo históricamente sus características particulares y se le impone una condición vinculada con lo mestizo, específicamente como una parte subordinada. En general, el pensamiento indianista sistematizado y teorizado por Reinaga aboga por releer la historia boliviana desde el punto de vista de los indios. Su finalidad consiste en reiniciar los estudios históricos sobre el papel protagonista que hayan ejercido en el curso histórico las naciones originarias, mayoritarias en la población, sintiendo así la nostalgia común frente al yugo colonialista y neocolonialista, y recordando las luchas rebeldes de los pueblos nativos.

Desde el punto de vista de García Linera, la revolución nacionalista de 1952 y las posteriores reformas agrarias efectuadas desde 1953, habían insuflado algunas aspiraciones a los indígenas. Así, se concebía una apertura a los indios en la medida en que se abrieron espacios para la posibilidad de un ascenso social por medio, por ejemplo, de su inclusión en la educación hegemónica del nacionalismo estatal. Sin embargo, nuevamente se efectuaba una configuración de plurietnicidad en términos culturales y sociales, pero una monoetnicidad en términos políticos y económicos. Todo ese planteamiento se llevó adelante a través de la extensión de la izquierda marxista, en la que la clase campesina se subordinó a la obrera. De tal modo que se puede decir que la etapa nacionalista boliviana se refiere a un proceso de descampesinización o de desetnización campesina ${ }^{5}$. Por ello, la profundización de la descampesinización, junto con los fracasos del proyecto nacionalista, darán lugar a la reivindicación de la razón colonialista propia de las élites dominantes. Debido a esta situación, se cerraron otra vez las puertas democráticas tanto al campesinado como a todos los elementos subalternos, la mayoría de los cuales son indígenas. Todas estas circunstancias, llenas de conflictos teleológicos e ideológicos que se dieron entre la parte dominante y la dominada de Bolivia, permitieron el surgimiento del indianismo frente a la subordinación indígena.

La iniciativa indianista persigue la construcción del sujeto político en torno a la autonomía de los pueblos nativos y por la vía de los movimientos revolucionarios. Así, busca promover la capacidad de autodecisión de los

\footnotetext{
A. García Linera, "Indianismo y Marxismo, el desencuentro de dos razones revolucionarias", Revista Cuadernos del Pensamiento Critico Latinoamericano, 3, 2007, p. 4.
} 
asuntos propios indígenas, rompiendo con las imposiciones de cualquier poder no-indígena. Por lo tanto, Reinaga no hace sino más potente la doctrina del incanista Luis Eduardo Valcárcel ${ }^{6}$ en torno a la recomprensión de la civilización incaica y que busca recuperar el discurso indígena ${ }^{7}$. De esta manera, Valcárcel, el fundador peruano del indigenismo, dio la argumentación teórica e histórica a Reinaga, gracias a la cual este pudo retomar la cuestión indígena y así ejercer una nueva valoración de la Bolivia europeizada y mestiza. En este sentido, podemos decir que el indianismo no surge por negación del indigenismo; surge para enriquecer y mejorar el indigenismo pero desde un punto de vista más indianizado.

Según Fabiola Escárzaga, la vida ideológica de Fausto Reinaga puede dividirse en dos periodos: el marxista (1930-1960) y el indianista (1960-1994) ${ }^{8}$. Esta transformación del marxismo al indianismo pone en manifiesto explícitamente la desesperanza de Reinaga y su ruptura con el marxismo. ¿Por qué sucedió esto? Porque en aquellos momentos los marxistas latinoamericanos, aunque enarbolaban la inclusión del pueblo indígena, preferían construir una nación mestiza antioligárquica con la alianza de los indígenas, enfatizando la fuerza obrerista mestiza y a la vez subordinando la fuerza campesinista indígena. Como su representante, José Carlos Mariátegui ${ }^{9}$ confirma de nuevo la contribución de los indios en la historia con el objetivo de construir el nuevo socialismo indigenista, aprovechándose de la memoria popular que la comunidad indígena del Ayllu tenía sobre el comunismo primitivo. Así que Mariátegui aboga por construir un Estado de carácter nacional mestizo incorporando para ello a los indios bajo una lógica de mestizaje por medio de la revolución socialista. En cambio, Reinaga propende a la revolución india ${ }^{10}$. Esta divergencia marca la ruptura entre Reinaga y Mariátegui en torno al estatus del protagonista de la revolución que ha de llevar a la nación hacia un Estado más democratizado $^{11}$. En realidad, el indigenismo de Mariátegui era de naturaleza mítica, y no verdaderamente étnico cultural y antropológico. Influido por la teoría de la huelga general como mito del socialismo, la cual defendían los pensadores europeos, Mariátegui buscaba identificar un sujeto capaz de verse como revolucionario en sentido marxista, es decir, su indio prototípico actor de la revolución es sencillamente un seguidor de Marx que se reconoce como indio, pero no en tanto que indio.

El indianismo, la ideología asumida por Reinaga, tiene dos tareas fundamentales: por un lado, profundizar en las luchas antirracistas y anticolonialistas; por otro, mantener una interpelación constante con la lógica liberal acerca de la meta de la democracia, per-

\footnotetext{
6 W. Espinosa Soriano, "Luis E. Valcárcel, el indigenista e incanista", Revista Ciencias Sociales, 1, 1995, pp. 69-82.

F. Escárzaga, op. cit., pp. 72-73.

Ibidem, p. 74.

J. Sánchez Rodríguez, José Carlos Mariátegui y Álvaro García Linera, dos representantes en los extremos de la historia del marxismo latinoamericano, 2017. Cf. en < http://miradacrtica.blogspot.com. es/2017/04/jose-carlos-mariategui-y-alvaro-garcia.html> (Consulta: el día 11 de septiembre de 2017).

10 F. Reinaga, La revolución india, La Paz, MINKA, 2010.

11 F. Escárzaga, "La huella de Mariátegui en Fausto Reinaga", Revista América Latina, 13, 2012, pp. 237-286.
}

siguiendo así la autoliberación de la nación indígena. Cuando se habla de las luchas en contra del racismo y del colonialismo, no cabe duda de que se refieren a las acciones revolucionarias descolonizadoras. Es decir, la primera tarea indianista consiste en construir un sentido común descolonizado o que busque la descolonización. Pues bien, esta línea de pensamiento está de acuerdo con los planteamientos propuestos en Los condenados de la tierra, la obra culminante de Frantz Fanon, en la que el autor nos demuestra los crímenes anticivilizatorios cometidos por el colonialismo, los cuales convocaron a las luchas anticoloniales, y a la vez desplegaron el proceso de descolonización. Fanon consideró al racismo como al mayor opositor al proceso descolonizador, con lo cual puede admitirse que el racismo y las identidades que surgen durante la etapa de la colonización son ambos adversarios de los pueblos indígenas. Aparte de eso, Fanon enarboló la bandera de la violencia como medio de lucha contra la violencia. "El colonialismo no es una máquina de pensar, no es un cuerpo dotado de razón. Es la violencia en estado de naturaleza y no puede inclinarse sino ante una violencia mayor"12. Es decir, con respecto a la violencia colonial no hay otra manera eficaz de aplacarla que con una violencia mayor capaz de quebrantar el colonialismo en su conjunto. La violencia sería la única forma de conseguir la plena liberación en contra de lo colonial. La revolución violenta o armada será el modo exclusivo de ejercer la tarea anticolonialista no solo para los oprimidos africanos, de los que habla Fanon, sino también para todos los colonizados que hay en el mundo ${ }^{13}$.

El uso de la violencia en la lucha anticolonial asumido por Fanon coincide con el maoísmo ${ }^{14}$, y ha dejado una marca fundamental en el pensamiento de Fausto Reinaga en torno a la revolución armada indígena. Otra influencia de Fanon sobre aquel será Piel negra, mascaras blancas gracias a la cual Reinaga percibe la crisis sustancial del Estado liberal bajo una aparente paz superficial, y que consiste en ocultar las tensiones irreconciliables entre dos grupos, los dominantes neocolonizadores y los dominados neocolonizados. La salida a tales tensiones reside en la fuerza de las luchas anticoloniales y descolonizadoras, reconstruyendo así una Nación nueva desde el fundamento histórico encontrado en los mismos elementos subalternos, y cuestionando el modo occidentalizado. Por ello, el indianismo de Reinaga se decanta por la revolución del pueblo indio.

En suma, se puede decir que el indianismo propuesto por Fausto Reinaga se trata de una ideología de autoidentificación, autodeterminación, autoliberación y autonomía de los pueblos indígenas, vinculada con los

12 F. Fanon, Los condenados de la tierra, México, D. F., Fondo de Cultura Económica, 2011, p. 30.

13 D. Gabriel Dolgopol, "Comentario a «Los condenados de la Tierra», de Frantz Fanon, y de su prefacio de Jean Paul Sartre”, Revista de Claseshistoria, 399, 2013, pp. 1-16.

14 M. Tse-tung, "Un informe sobre la investigación del Movimiento Campesino en JUNÁN", en Obras Escogidas de Mao Tse-tung I, Pekin, Ediciones En Lenguas Extranjeras, 1976, pp. 19-20. En esta obra Mao determina y admite el tipo de violencia requerido en los movimientos revolucionarios del campesinados en contra de los reaccionarios feudales y militaristas. 
pensamientos de Valcárcel en torno a la reorganización de las estructuras comunitarias indígenas, con el de Mariátegui respecto del reconocimiento de la base social comunista de la comunidad indígena, y con el de Fanon en torno al uso de la violencia en la revolución india y la autoproducción de la lógica anticolonial y descolonizadora. Así, el surgimiento del indianismo proyecta en el mercado político americano un horizonte de amplias posibilidades para la implantación de los programas estatales de las naciones indígenas, sobre todo en Bolivia.

\section{Indianismo, katarismo y Álvaro García Linera}

Como ex-miembro del grupo guerrillero EGTK, García Linera postula un indianismo-katarista acentuando la condición auxiliar del katarismo respecto del indianis$\mathrm{mo}^{15}$. El indianismo y el katarismo son dos pensamientos indígenas coetáneos, iniciados en la década de los 70 con motivo del fracaso de la modernización nacionalista mestiza, y que condenan firmemente la colonización. Bajo la perspectiva de García Linera, el indianismo procura "luchar por el poder del Estado para indianizar Bolivia"16, mientras que el katarismo pretende tomar el poder en alianza con los campesinos indígenas por medio de la organización sindical. Además, los incipientes indianistas rechazan las fuerzas progresistas procedentes de las izquierdas marxistas, y en cambio los kataristas buscan el diálogo con ellas. En este sentido, respecto a la forma revolucionaria más conveniente, podemos decir que la vertiente indianista es más radical que la katarista, y que prefiere una Bolivia indianizada. Así, la temática de las "dos Bolivias" será el factor indianista más polémico, motivo por el cual el indianismo recibe mayores interpelaciones de sus adversarios; por ejemplo, las de algunos kataristas como Silvia Rivera, que cuestionan al indianismo como si fuera otro tipo de racismo ${ }^{17}$.

El indianismo katarista que postula García Linera pone de manifiesto la intención de romper el desencuentro entre el indianismo y el marxismo, deseando que "se unifique el mundo urbano-obrero con el mundo agrariocampesino indígena"18. En cierto modo, la única forma legítima de incorporación a lo político en los Estados modernos debe serlo de una manera democrática, y la que tiene este carácter y a la vez es más directa y factible debiera ser la "lucha electoral". Por tal motivo, tanto el

15 A. García Linera, "Indianismo y Marxismo, el desencuentro de dos razones revolucionarias", op. cit. pp. 6-7.

16 A. García Linera, "Nuestra América, Marxismo e indianismo", Revista Tareas, 131, 2008, p. 115.

17 P. Velásquez Mamani, ¿Qué es el indianismo-katarismo? 2016. Cf. en <http://jichha.blogspot.com.es/2016/04/que-es-el-indianismokatarismo-pablo.html>. (Consulta: el 29 de agosto de 2017.)

18 A. García Linera, Nuestra América, Marxismo e indianismo, op. cit., p. 116. García Linera manifiesta esta propuesta dado que las fuerzas de izquierda marxistas enarbolan el obrerismo en las zonas urbanas, en las que la mayoría de ciudadanos son de clase obrera, mientras que en las zonas rurales el indianismo logra más simpatizantes. La unión de estas dos zonas significa la poderosa articulación del movimiento indianista con el del katarista marxista, lo que dará lugar a la modificación radical del indianismo por la que aceptará a los izquierdistas. Desde este momento, los movimientos políticos latinoamericanos se caracterizarán por poseer dos ideologías indianizadas, el indianismo y el marxismo heterodoxo. indianismo como el katarismo materializan la primera memoria indígena vertida en un proceso electoral, que ocurrió en los años 1978-80 a través de sus correspondientes partidos, el MITKA (Movimiento Indio Túpac Katari) y el MRTK (Movimiento Revolucionario Túpac Katari). Desde esta perspectiva, García Linera defiende que una competencia electoral entre el indianismo y el katarismo tendría como consecuencia ineludible el debilitamiento del katarismo y la desintegración del indianismo $^{19}$. En este sentido, la propuesta de García Linera implica la formación de un solo bloque histórico con la suma de dos fuerzas que antaño se veían como antagónicas. A su decir esa sería la única posibilidad de forjar una lucha hegemónica.

Aun cuando configuraron divergentes estrategias políticas, el tópico fundamental tanto para el indianismo como para el katarismo consiste en la posición de centralidad de lo indígena. En este sentido, la tématica indígena va haciéndose más dinámica y fructífera en torno a los aportes políticos y culturales que se hacen desde varias tendencias. En cierto modo, se puede decir que la cristalización del indianismo se centra en la materialización de la identificación del pueblo indígena aymara; es decir, en el caso de Bolivia, la identificación de lo indígena, que abarca muchas etnias nativas, debería ser implantada a partir de los aymaras, los cuales son numéricamente mayoritarios entre los indígenas y además han sido más activistas a lo largo de la historia. La centralidad de la identidad aymara en sus luchas por la autoliberación y autodeterminación determinó un movimiento expansivo por el que las demás naciones indígenas autoafirmaron sus trayectorias identitarias. Todo esto coincide con la táctica marxista sobre la autodeterminación de los subalternos, y aquí se trata de las luchas indígenas. Esta vinculación del pensamiento de lo indígena respecto con el marxismo crítico permite que el indianismo amplíe su atención hacia terrenos más extensos y en sectores sindicales urbano-obreros. De este modo, en el futuro lo indígena podrá desplegarse como el discurso nacional mayoritario y se abrirán posibilidades para la alianza entre el marxismo y el indianismo.

El indianismo pretende hacer del sujeto social mayoritario el sujeto político principal y así sujeto mandatario. En este sentido, lo que anhelan los indianistas ya no es el reconocimiento nacionalista que puede girar en torno a la etnicidad y la nacionalidad, sino la misma gobernación de Bolivia ${ }^{20}$. Por eso, el indianismo no reduce su aspiración a la autogobernación,

19 Ibidem. En esta coyuntura de 1982, los kataristas dirigidos por Genaro Flores obtienen la posibilidad de cogobernar con la izquierda UDP (Unidad Democrática Popular) mediante un sistema de coalición. Este hecho consistirá en la cima de la vida política del katarista, y desde acá no se buscará ningún tipo de alianza electoral con otros movimientos o partidos porque ellos mismos no podrán presentarse a las elecciones de forma autónoma debido a su incapacidad para gobernar independientemente. Debido a este hecho, los kataristas irán declinando en importancia y erosiánondose en diferentes posturas que irán adoptando otros idearios, como el indianista. Por otra parte, al mismo tiempo, el indianismo se dividirá en varias partes, la religiosa, la intelectual y la que busca la alianza con las fuerzas conservadoras para conseguir la victoria electoral.

20 P. Portugal Mollinedo, y C. Macusaya Cruz, El indianismo katarista, un análisis crítico, La Paz, Fundación Friedrich Ebert (FES), 1999, p. 24. 
sino que va incluso más allá, hasta la toma del poder estatal. En el caso de Bolivia, el florecimiento del neoliberalismo ha cambiado de manera formidable las estructuras productivas nacionales, y la libre importación, en lugar de la producción agraria tradicional, se ha convertido en la principal forma productiva de la sociedad boliviana. De este modo, a medida que se ha impuesto el neoliberalismo, el sistema económico clásico ha venido sufriendo mayores ataques y degradaciones. Estos factores han dado lugar al estancamiento de reproducción del sistema social, a la vez que han impulsado como respuesta la articulación entre las zonas urbanas y las rurales, o aun entre las mismas comunidades indígenas, con el objetivo de retomar la reproducción colectiva de los bienes y de la vida en común, luchando así contra los riesgos generales provenientes del sistema de importación neoliberal. En consecuencia, los indianistas campesinos han logrado tener la oportunidad de colaborar con los izquierdistas obreristas urbanos. De esta manera, la vertiente indianista ha logrado una modificación radical en la actualidad histórica, introduciendo en sí misma la tarea antiimperialista. Esta corriente viene transformándose desde los años 90 en un indianismo de corte izquierdista dentro del cual el MAS acabará siendo el movimiento más representativo ${ }^{21}$.

Dado que el indianismo se opone profundamente a la dominación de la población mestiza ejercida desde la jerarquía heredada del colonialismo, aquel se ha visto en la necesidad de impugnar los elementos básicos del nacionalismo revolucionario, que son la casta criolla, la historia colonial, la cultura hispánica y algunos otros, todos ellos testimonios de esa violencia primitiva sobre los que ejercer la descolonización. Al mismo tiempo, eso pretende el indianismo, todos esos elementos volverán a ser legitimados y politizados, pero esta vez desde el proyecto indianista. Los campesinos, que son la fuerza fundamental del indianismo, se concentran en la problemática relativa a la tierra, así que por ejemplo la "Guerra de Agua", iniciada en el año 2000, y la "Guerra de Gas", en el 2003, han dado lugar a continuos movimientos indígenas en las zonas rurales, y también a otros obreros en las zonas urbanas. A partir de aquí, la alianza entre el indianismo y el marxismo ha avanzado desde aquella mera posibilidad virtual de unión de indianismo y katarismo hasta la facticidad práctica, capaz de orientar las luchas políticas desde un principio común.

Conforme a lo propuesto por García Linera, hoy en día el indianismo es la nueva izquierda política, debido a que, por una parte, el indianismo en el Estado plurinacional ostenta una intensa vinculación con el marxismo, es decir, porque se trata de un indianismo heterodoxo virado a la izquierda; y por otra parte, porque el indianismo retoma a la clase campesina como la potencia radical de la revolución plurinacional socialista, a diferencia del marxismo ortodoxo, que es proclive a la clase obrera. En otras palabras, García Linera se orienta por un marxismo heterodoxo indianizado. En este sentido, el indianismo será el modelo imprescindible

A. García Linera, "Indianismo y Marxismo, el desencuentro de dos razones revolucionarias", op. cit., pp. 10-11. para la construcción de la plurinacionalidad a causa de su naturaleza descolonizadora.

En cambio, hoy en día algunos intelectuales cuestionan al indianismo al tildarlo de retroceso dentro de la historia, realizando una descalificación que lo retira como base de la civilización moderna. En consonancia con lo propuesto por H. C. F. Mansilla ${ }^{22}$, el indianismo asumido por Fausto Reinaga, y con los sustentadores posteriores de esta posición, tiene como objetivo fundamental la descolonización. Así que en este movimiento, según piensan algunos intelectuales, los indianistas "evidencian la intención oculta de desconocer el valor y el potencial de lo que la civilización occidental logró en el pasado y continúa realizando en el siglo XXI'"23. Siguiendo con esta lógica, todos los asuntos relacionados con la civilización occidental están enfrentados al indianismo, por lo que los indianistas niegan el sistema político, la filosofía del poder, la modernización, la globalización y otros factores occidentalizados que ya existen en Bolivia, lo que no quita para que a la vez sigan disfrutando de las oportunidades positivas de la industrialización, las ciencias y las tecnologías, ostentando una vida cotidiana occidentalizada, usando el idioma español y los trajes modernos, y otros productos directos e indirectos de la civilización occidental. $\mathrm{Y}$ en realidad, los indianistas no rechazan la civilización occidental, sino un pueblo indígena subalternizado y una América occidentalizada.

Otros pensadores tienen consideraciones que van en un sentido contrario, como Franco Gamboa Rocabado, para quien "el indio es una nación y una cultura que lucha por su plena autodeterminación" 24 . Es cierto, no obstante, que para Gamboa el indio es el tema sustancial del indianismo, la autoderminación implica la autoemancipación, y esta se consuma con la autogobernación y la autonomía. El indianismo concibe un proyecto descolonizador para todas las naciones indígenas, lo que sitúa a Gamboa en un horizonte que tiene los mismo fines que la teorización de García Linera. Sin embargo, para este, durante la etapa de la implantación el indianismo se materializa por medio de una nación indígena específica, la aymara. Desde luego los aymaras son mayoritarios en la población indígena y además presentan una historia continua de luchas por la autonomía contra todas las opresiones más largas respecto a las otras naciones nativas. En cierto modo, la nación aymara es la más representativa y la más poderosa de todas las indias, y la que más ha trabajado en favor de la restauración del poder indígena. Empero, el indianismo de García Linera, orientado por la identidad aymara, presenta la vulnerabilidad y el desequilibrio de las etnias indígenas durante el proceso de la construcción de plurinacionalidad. De este modo, las identidades aymaras se transformarán en el único sentido común indígena, subalternizando a las otras indígenas. Desde este punto de vista, se puede decir que el indianismo generará autoetnocidio o neorracismo.

\footnotetext{
H. C. F. Mansilla, Una mirada crítica al indianismo y a la descononización, La Paz, Rincón Ediciones, 2014.

23 B. Lozada Pereira, "La mirada crítica de Mansilla sobre el indianismo", Revista Pukara, 97, 2014, p. 6.

24 F. Gamboa Rocabado, "Bolivia frente a su espejo: el indianismo, sus orígenes y limitaciones en el XXI", Revista Estudios Sociológicos, 83, 2010, p. 536 .
} 
En cierta manera, estas dos críticas al indianismo tienen su particular modo de pensar y su propio soporte teórico. Sin embargo, Mansilla interpela al indianismo con ciertos malentendidos que distingue en su seno: "En su etapa indianista Reinaga llega a la conclusión central de que todo el pensamiento occidental desde Sócrates a Marx representa una sola lógica de dominación basada en la mentira y el crimen"25. Desde luego, el racismo y la colonización son dos partes negativas del pensamiento occidental, pero no todas ellas son así. De la civilización occidental también se pueden extraer argumentos como el del antirracismo y la descolonización, por lo que aquellos fenómenos no pueden implicar la denegación completa a la civilización occidental. Como indica Mao, la mejor forma de estimular nuestra creatividad consiste en la inspiración en los méritos de los adversarios ${ }^{26}$. De este modo, rechazar por completo el pensamiento occidental se trata de una acción imprudente que opone de manera absoluta el indianismo a la lógica occidental y deja en evidencia a García Linera. Sin embargo, los indianistas contemporáneos no son tan imprudentes. Aunque la crítica de Mansilla se sostiene desde un punto de vista fehacientemente falso ${ }^{27}$, sí que nos ha transmitido una reflexión sobre el indianismo por la cual este ha sido capaz de realizar una autocrítica dispuesta a reconocer que la civilización occidental maneja siempre la dualidad, siendo posible que esta sea a la vez moderna y tradicional, liberal y conservadora, racista y antirracista en la misma sociedad y por medio de las instituciones llamadas democráticas.

Con respecto a la crítica de Rocabado, me parece que el indianismo que él critica no tiene nada que ver con el racismo o el neorracismo. La base del racismo es la raza, una clasificación artificial de la gente mediante la distinción en el color de la piel, la cultura, la historia y otros factores, con la finalidad de legitimar las actividades coloniales. Tal operación no sucede en la práctica de las luchas aymaras, que él cuestiona por tanto de una manera indebida. Tampoco se trata por otra parte del autoetnocidio desde luego, pues la indianización dirigida por los aymaras no implica una imposición, sino una hibridación cultural interior a las naciones indígenas. Aunque ese comentario es alarmista, nos hace meditar el indianismo de manera diferente. En realidad, todo eso se trata de cuestionar las limitaciones y desafíos de esta nueva izquierda. Con estas reflexiones aspiramos a que el indianismo pueda mantener de una manera perdurable la autocrítica, la autoproducción y el automejoramiento.

Puesto que en cierto modo García Linera rompe el desencuentro entre marxismo e indigenismo, su indianismo se ha vinculado con las nuevas transformaciones producidas en el marxismo. Para Marx, recordemos, la superestructura está condicionada fuertemente por la infraestructura económica, pero no determinada por completo. De hecho, el marxismo cuestiona y critica este incorrectamente referido determinismo económico. Así, el indianismo de García Linera apareció en la arena política no a través de una aportación económica realizada por los grupos indígenas, sino por la importancia cultural que le ha otorgado la comunidad indígena a la formación de la plurinacionalidad boliviana. En este sentido, el indianismo rompe con la regla del determinismo económico, y de esta manera coincide con el marxismo. Dada esta vinculación entre indianismo y marxismo heterodoxo, la teleología del indianismo ya no trata de forjar por tanto un pensamiento utópico, sino de concentrar en lo concreto una nueva forma de pensar, anclada en los intereses de los grupos indígenas. Todo esto permite asumir nuevos sujetos políticos en la escena nacional, fuera de la centralidad tradicionalmente otorgada a la clase trabajadora $\mathrm{y}$, por tanto, abrirse a actores indígenas que antes eran contemplados solo como subordinados al llamado "sujeto histórico" que encarnaba la transformación política.

\section{Bibliografía}

Escárzaga, F., "El pensamiento indianista de Fausto Reinaga”, La Migraña, Revista de análisis político, 20, 2016.

-, "La huella de Mariátegui en Fausto Reinaga", Revista América Latina, 13, 2012.

Espinosa Soriano, W., "Luis E. Valcárcel, el indigenista e incanista”, Revista Ciencias Sociales, 1, 1995.

Fanon, F., Los condenados de la tierra, México, D. F., Fondo de Cultura Económica, 2011.

Gabriel Dolgopol, D., "Comentario a «Los condenados de la Tierra», de Frantz Fanon, y de su prefacio de Jean Paul Sartre", Revista de Claseshistoria, 399, 2013.

Gamboa Rocabado, F., "Bolivia frente a su espejo: el indianismo, sus orígenes y limitaciones en el XXI", Revista Estudios Sociológicos, 83, 2010.

García Linera, Á., "Indianismo y Marxismo, el desencuentro de dos razones revolucionarias”, Revista Cuadernos del Pensamiento Crítico Latinoamericano, 3, 2007.

-, "Nuestra América, Marxismo e indianismo", Revista Tareas, 131, 2008.

-, La potencia plebeya, Buenos Aires, Prometeo-Clasco, 2008.

\footnotetext{
H. C. F. Mansilla, op. cit., p. 118.

26 M. Tse-tung, "El pueblo chino se ha puesto en pie", en Obras Escogidas de Mao Tse-tung, Tomo V, Pekin, Ediciones En Lenguas Extranjeras, 1976, pp. 11-15.

27 C. Macusaya, "Reinaga y Mansilla: Presunciones y vacíos en un intento de crítica al indianismo", Revista Pukara, 97, 2010, p. 10. "La preocupación que guía el trabajo de Mansilla es la descalificación del adversario, hasta llegar a la caricatura [...]."
} 
Lozada Pereira, B., "La mirada crítica de Mansilla sobre el indianismo", Revista Pukara, 97, 2014.

Macusaya, C., "Reinaga y Mansilla: Presunciones y vacíos en un intento de crítica al indianismo", Revista Pukara, 97, 2010.

Mansilla, H. C. F., Una mirada crítica al indianismo y a la descononización, La Paz, Rincón Ediciones, 2014.

Tse-tung, M. "El pueblo chino se ha puesto en pie", en Obras Escogidas de Mao Tse-tung, Tomo V, Pekin, Ediciones En Lenguas Extranjeras, 1976.

-, "Un informe sobre la investigación del Movimiento Campesino en JUNÁN", en Obras Escogidas de Mao Tse-tung, Tomo I, Pekin, Ediciones En Lenguas Entranjeras, 1976.

Portugal Mollinedo, P. y Macusaya Cruz, C., El indianismo katarista, un análisis crítico, La Paz, Fundación Friedrich Ebert (FES), 1999.

Reinaga, F., La revolución india, La Paz, MINKA, 2010.

Sánchez Rodríguez, J., José Carlos Mariátegui y Álvaro García Linera, dos representantes en los extremos de la historia del marxismo latinoamericano, 2017. Cf. en http://miradacrtica.blogspot.com.es/2017/04/jose-carlos-mariategui-y-alvarogarcia.html.

Sánchez, C., Los pueblos indigenas: del indigenismo a la autonomía, México, D.F., Siglo XXI, 1999.

Velásquez Mamani, P., ¿Qué es el indianismo-katarismo? 2016. Cf. en http://jichha.blogspot.com.es/2016/04/que-es-elindianismo-katarismo-pablo.html. 